\title{
Best proximity point results for Hardy-Rogers $p$-proximal cyclic contraction in uniform spaces
}

\author{
Victoria O. Olisama ${ }^{1 *}$, Johnson O. Olaleru² and Hudson Akewe ${ }^{3}$
}

"Correspondence:

vicolisama@yahoo.com

'Department of Mathematics,

Adeniran Ogunsanya College of

Education, Lagos, Nigeria

Full list of author information is

available at the end of the article

\section{严 Springer}

\begin{abstract}
The Hardy-Rogers p-proximal cyclic contraction, which includes the cyclic, Kannan, Chatterjea and Reich contractions as sub-classes, is developed in uniform spaces. The existence and uniqueness results of best proximity points for these contractions are proved. The results, which are for non-self maps, apart from the fact that they are new in literature, generalise several other similar results in literature. Examples are given to validate the results obtained.
\end{abstract}

MSC: $47 \mathrm{H} 10 ; 54 \mathrm{H} 25$

Keywords: Best proximity point; Cyclic contraction; Hardy-Rogers cyclic contraction; $p$-proximal contraction; Uniform spaces

\section{Introduction}

There are several metrical fixed point theorems for self-mappings satisfying certain contractive type conditions. In each of these results, the authors consider sequences of iterates which, due to the contractive conditions, become Cauchy sequences whose limits are fixed points of the mappings. Research on the fixed points of contractive maps has become a centre of strong research activity for many researchers in mathematics. The reason being that the applications of fixed point theory play a basic role in various areas of mathematics. It provides a technique for solving a variety of applied problems in many branches of mathematics, see [8, 12, 18, 22, 27]. It now has applications in fields such as computer science, engineering, chemistry, biology, economics and statistics.

In 1922, Stefan Banach (1892-1945) popularised the research in metrical fixed point theory with the famous Banach contraction principle [4]. Since then, several authors have established fixed point results for numerous contraction mappings in metric spaces. Rhoades [29] made a comparison of different types of contraction mappings including Kannan [15], Chatterjea [7], Reich [28], Ciric [9], Zamfirescu [32] and Hardy and Rogers [13].

If the mapping under consideration is not a self-mapping, say $T: A \rightarrow B$ where $A, B$ are nonempty subsets of $X$, then $T$ does not necessarily have a fixed point. It is therefore of interest to determine an element $x$ called the best proximity point that is in some sense closest to $T x$. The aim of the best proximity point theorem is to provide sufficient

(c) The Author(s) 2018. This article is distributed under the terms of the Creative Commons Attribution 4.0 International License (http://creativecommons.org/licenses/by/4.0/), which permits unrestricted use, distribution, and reproduction in any medium, provided you give appropriate credit to the original author(s) and the source, provide a link to the Creative Commons license, and indicate if changes were made. 
conditions to ascertain the existence of an optimal solution to the problem of globally minimising the error $d(x, T x)$, see [11]. Since $d(x, T x) \geq d(A, B)$ for all $x$, a best proximity point theorem offers sufficient conditions for the existence of an element $x$, satisfying the condition that $d(x, T x)=d(A, B)$, which is the optimal solution in the sense that $d(x, T x)$ is minimum. The best proximity point is a natural generalisation of fixed point for it reduces to a fixed point if the mapping under consideration is a self-mapping. The notion of best proximity point was introduced in [19].

Best proximity point theory of a cyclic contraction map has been studied by many authors. For results regarding cyclic contractive conditions when the intersection of the sets is nonempty, see $[2,16]$. In [11], Eldred and Veeramani extended the cyclic contractive condition above to the case when $A \cap B$ is empty and proved the existence of best proximity point. For further results in this area, see $[3,5,17,20,23,25,26,30]$.

Further improvement on the Banach contraction principle includes the use of uniform spaces rather than the metric spaces. One of the spaces in literature that generalises the metric space is the uniform space. Weil [31] was the first to introduce uniform spaces in terms of a family of pseudometrics, and Bourbaki [6] provided the definition of a uniform structure in terms of entourages.

Aamri and El Moutawakil [1] gave some results on a common fixed point of some contractive and expansive maps in uniform spaces and introduced the definitions of $A$ distance and $E$-distance. Also, Dhagat et al. [10] proved some common fixed point theorems for pairs of weakly and semi-compatible mappings with the notation of $E$-distance in uniform spaces. Hussain et al. [14] applied the concept of cyclic $(\psi)$-contractions to establish certain fixed and common point theorems on a Hausdorff uniform space. But none of these authors have worked on Kannan, Chatterjea, Reich and Hardy-Rogers contractions in uniform spaces.

It is also interesting to note that all those results in uniform spaces are of self-mappings, but to the best of authors' knowledge, few results of non-self mappings in uniform spaces exist in literature (see [24]).

In 2011, Basha [5] established some necessary and sufficient conditions for the existence of a best proximity point for proximal contraction which are analogues of non-self contractive mappings and also gave some best proximity and convergence theorems. But the authors are yet to popularise the results of best proximity point of proximal contractions in uniform spaces.

Furthermore, Karapinar and Erhan [16] introduced the Kannan, Chatterjea and Reich cyclic contractions and proved the fixed point theorems for these maps.

Also, Mihaela [20] introduced a new class of cyclic contractions, called the weak cyclic Kannan contractions, and gave sufficient conditions for the existence of a unique best proximity point of these maps. But to the best of the authors' knowledge, no work has been extended to the best proximity points of Hardy-Rogers type mappings in uniform spaces.

Motivated by the results above, the authors introduce a modified class of Hardy-Rogers $p$-proximal cyclic contractions in uniform spaces and establish the best proximity point results for this type of contractions in uniform spaces.

\subsection{Methods}

The source of the materials used in this study include past and current journal articles and text books. These relevant materials were obtained by searching through the Inter- 
net. The authors of these materials with well-known results are internationally recognised experts in this area of study. The study includes the related works on fixed point and best proximity point theory. The maps, on the other hand, are used to obtain the existence of best proximity points of Hardy and Rogers $p$-proximal cyclic contractive maps in uniform spaces. To show our results, modified and simpler methods are used.

\subsubsection{Aim}

The aim of this study is to extend the fixed point results for self-maps in metric spaces to best proximity point results for non-self Hardy-Rogers $p$-proximal cyclic contractive map in uniform spaces.

\section{Preliminary}

Here are some basic definitions and concepts relating to the main result of this paper.

A uniform space $(X, \Gamma)$ is a non-empty set equipped with a uniform structure, which is a family $\Gamma$ of subsets of Cartesian product $X \times X$, satisfying the following conditions:

(i) If $U \in \Gamma$, then $U$ contains the diagonal $\Delta=\{(x, x): x \in X\}$.

(ii) If $U \in \Gamma$, then $U^{-1}=\{(y, x):(x, y) \in U\}$ is also in $\Gamma$.

(iii) If $U, V \in \Gamma$, then $U \cap V \in \Gamma$.

(iv) If $U \in \Gamma$ and $V \subseteq X \times X$, which contains $U$, then $V \in \Gamma$.

(v) If $U \in \Gamma$, then there exists $V \in \Gamma$ such that whenever $(x, y)$ and $(y, z)$ are in $V$, then $(x, z)$ is in $U$.

Note that $\Gamma$ is called the uniform structure or uniformity of $X$ and its elements are called entourages, neighbourhoods, surroundings or vicinities, see [6].

A uniform structure $\Gamma$ defines a unique topology $\tau(\Gamma)$ on $X$ for which the neighbourhoods of $x \in X$ are the sets $V(x)=\{y \in X:(x, y) \in V\}, V \in \Gamma$.

We recall the following definitions in uniform spaces.

Definition 2.1 ([1]) Let $(X, \Gamma)$ be a uniform space. A function $p: X \times X \rightarrow R^{+}$is said to be an

(a) $A$-distance if, for any $V \in \Gamma$, there exists $\delta>0$ such that if $p(z, x) \leq \delta$ and $p(z, y) \leq \delta$ for some $z \in X$, then $(x, y) \in V$;

(b) $E$-distance if $p$ is an $A$-distance and $p(x, y) \leq p(x, z)+p(z, y)$ for all $x, y, z \in X$.

Definition $2.2([1])$ Let $(X, \Gamma)$ be a uniform space and $p$ be an $A$-distance on $X$.

(a) If $V \in \Gamma,(x, y) \in V$ and $(y, x) \in V$, then $x$ and $y$ are said to be $V$-close, and a sequence $\left\{x_{n}\right\} \in X$ is a Cauchy sequence for $\Gamma$ if, for any $V \in \Gamma$, there exists $N \geq 1$ such that $x_{n}$ and $x_{m}$ are $V$-close for $n, m \geq N$.

(b) A sequence in $X$ is $p$-Cauchy if it satisfies the usual metric condition.

(c) $X$ is $S$-complete if, for every $p$-Cauchy sequence $\left\{x_{n}\right\}$, there exists $x \in X$ such that $\lim _{n \rightarrow \infty} p\left(x_{n}, x\right)=0$. And $X$ is $p$-Cauchy complete if, for every $p$-Cauchy sequence $\left\{x_{n}\right\}$, there exists $x \in X$ such that $\lim _{n \rightarrow \infty} x_{n}=x$ with respect to $\tau(\Gamma)$.

(d) $f: X \times X$ is $p$-continuous if $\lim _{n \rightarrow \infty} p\left(x_{n}, x\right)=0$ implies $\lim _{n \rightarrow \infty} p\left(f\left(x_{n}\right), f(x)\right)=0$.

(e) $X$ is said to be $p$-bounded if $\delta_{p}(X)=\sup \{p(x, y): x, y \in X\}<\infty$.

Definition 2.3 ([1]) A uniform space $(X, \Gamma)$ is said to be Hausdorff if and only if the intersection of all $V \in \Gamma$ reduces to the diagonal $\Delta$ of $X$. For example, $(x, y) \in V$ for all $V \in \Gamma$ implies $x=y$. This guarantees the uniqueness of the limits of the sequences. 
The following lemma, which is true for self-mappings (see Lemma 2.4 [1]), can be proved for non-self mappings.

Lemma 2.4 Let $(X, \Gamma)$ be a Hausdorff uniform space and $p$ be an A-distance on $X$. Let $\left\{x_{n}\right\}_{n=0}^{\infty},\left\{y_{n}\right\}_{n=0}^{\infty}$ be arbitrary sequences in $X$ and $\left\{\alpha_{n}\right\}_{n=0}^{\infty},\left\{\beta_{n}\right\}_{n=0}^{\infty}$ be sequences in $R^{+}$converging to 0 . Then, for all $x, y, z \in X$, the following hold:

(a) If $p\left(x_{n}, y\right) \leq \alpha_{n}$ and $p\left(x_{n}, z\right) \leq \beta_{n} \forall n \in N$, then $y=z$. In particular, if $p(x, y)=0$ and $p(x, z)=0$, then $y=z$.

(b) If $p\left(x_{n}, y_{n}\right)=p(A, B)$ and $p\left(x_{n}, z_{n}\right)=p(A, B)$, then $y_{n}=z_{n}, \forall n$.

(c) If $p\left(x_{n}, y_{n}\right) \leq \alpha_{n}$ and $p\left(x_{n}, z\right) \leq \beta_{n} \forall n \in N$, then $\left(y_{n}\right)_{n=0}^{\infty}$ converges to $z$.

(d) If $p\left(x_{n}, x_{m}\right) \leq \alpha_{n} \forall m>n$, then $\left(x_{n}\right)_{n=0}^{\infty}$ is a $p$-Cauchy sequence in $(X, \Gamma)$.

Let $A$ and $B$ be non-empty subsets of a uniform space $(X, \Gamma)$. We adopt the following notations to the context of uniform spaces when $p$ is an $E$-distance on $X$.

(i) $A_{0}=\{x \in A: p(x, y)=p(A, B)$ for some $y \in B\}$.

(ii) $B_{0}=\{y \in B: p(x, y)=p(A, B)$ for some $x \in A\}$.

(iii) Let $T: A \rightarrow B$, a point $x \in A$ is called a best proximity point if $p(x, T x)=p(A, B)$, where $p(A, B)=\inf \{p(a, b): a \in A, b \in B\}$.

In another development, Kirk et al. [19] defined cyclic map and cyclic contraction: Let $A$ and $B$ be nonempty subsets of a metric space $(X, d)$ and $T: A \cup B \rightarrow A \cup B . T$ is called a cyclic map if

(i) $T(A) \subseteq B$ and $T(B) \subseteq A$.

$T$ is a cyclic contraction if, for some $k \in[0,1)$,

(ii) $d(T x, T y) \leq k d(x, y)+(1-k) d(A, B) \forall x \in A, y \in B$.

Also, Karapinar and Erhan [16] gave the following definitions of different types of cyclic contractions and proved the existence of unique fixed points for maps (i)-(iii) below.

Definition 2.5 Let $(X, d)$ be a metric space and $A$ and $B$ be non-empty subsets of $X$. A cyclic map $T: A \cup B \rightarrow A \cup B$ is said to be a:

(i) Kannan type cyclic contraction if there exists $k \in\left(0, \frac{1}{2}\right)$ such that

$$
d(T(x), T(y)) \leq k[d(x, T(x))+d(y, T(y))], \quad \forall x \in A, \forall y \in B .
$$

(ii) Chatterjea type cyclic contraction if there exists $k \in\left(0, \frac{1}{2}\right)$ such that

$$
d(T(x), T(y)) \leq k[d(x, T(y))+d(y, T(x))], \quad \forall x \in A, \forall y \in B .
$$

(iii) Reich type cyclic contraction if there exists $k \in\left(0, \frac{1}{3}\right)$ such that

$$
d(T(x), T(y)) \leq k[d(x, y)+d(x, T(x))+d(y, T(y))], \quad \forall x \in A, \forall y \in B .
$$

Also, Hardy and Rogers type cyclic contraction states that there exist non-negative constants $a_{i}, i=1,2,3,4,5$, such that $a_{1}+a_{2}+a_{3}+a_{4}+a_{5}<1$ satisfying

$$
\begin{aligned}
d(T(x), T(y)) \leq & a_{1} d(x, y)+a_{2} d(x, T(x))+a_{3} d(y, T(y))+a_{4} d(x, T(y)) \\
& +a_{5} d(y, T(x))
\end{aligned}
$$

for all $x \in A$ and $y \in B$. 
Furthermore, Eldred and Veramani [11] presented some results using Kannan type contractions when $A \cap B=\emptyset$. In this case, they did not seek for the existence of a fixed point of $T$ but for the existence of a best proximity point. Motivated by the results of Eldred and Veramani for the case $A \cap B=\emptyset$, in this paper we present some best proximity point results for Hardy-Rogers $p$-proximal cyclic contraction in uniform spaces which is an analogue of the Hardy and Rogers results in [13], and a unification and extension of cyclic contraction, Kannan, Chatterjea and Reich cyclic contractions for non-self maps in uniform spaces.

Below are the definitions of proximal contraction in [5] and proximal cyclic contraction in [21].

Definition 2.6 ([5]) Let $(A, B)$ be a non-empty subset of a complete metric space $(X, d)$. A mapping $T: A \rightarrow B$ is said to be a proximal contraction if there exists a non-negative real number $\alpha<1$ such that

$$
\left\{\begin{array}{l}
d(u, T(x))=d(A, B) \\
d(v, T(y))=d(A, B)
\end{array} \quad \Longrightarrow \quad d(u, v) \leq \alpha d(x, y)\right.
$$

for all $u, x, v, y \in A$.

Definition 2.7 ([21]) Suppose that $(A, B)$ is a non-empty subset of a complete metric space $(X, d)$, and let $S: A \rightarrow B$ and $T: B \rightarrow A$ be mappings. The pair $(S, T)$ is called a proximal cyclic contraction pair if there exists $\alpha \in[0,1)$ such that

$$
\left\{\begin{array}{l}
d(a, S(x))=d(A, B) \\
d(b, T(y))=d(A, B)
\end{array} \quad \Longrightarrow \quad d(a, b) \leq \alpha d(x, y)+(1-\alpha) d(A, B)\right.
$$

for all $a, x \in A$ and $b, y \in B$.

Basha [5] proved the following theorem.

Theorem 2.8 ([5]) Suppose that $A, B$ are two nonempty subsets of a complete metric space $(X, d)$. Let $T: A \rightarrow B$ and $T\left(A_{0}\right)$ be nonempty and closed satisfying the following contractions:

(a) $T$ is a proximal contraction,

(b) $T\left(A_{0}\right) \subseteq B_{0}$.

Then there exists a point $x \in A$ such that $d(x, T(x))=d(A, B)$. Moreover, if $T$ is injective on $A$, then the point $x$ such that $d(x, T(x))=d(A, B)$ is unique.

Now, we introduce some analogues of Hardy and Rogers non-self proximal maps in uniform spaces.

Definition 2.9 Let $(A, B)$ be a pair of non-empty subsets of an $S$-complete Hausdorff uniform space $(X, \Gamma)$ such that $p$ is an $E$-distance on $X$. A mapping $F: A \rightarrow B$ is said to be a Hardy-Rogers $p$-proximal contraction if there exist non-negative real constants $U, V, C$, 
$D, W$ such that $U+V+C+D+W<1$ and for all $j, l, k, m \in A$,

$$
\begin{aligned}
& \left\{\begin{array}{l}
p(j, F(k))=p(A, B) \\
p(l, F(m))=p(A, B)
\end{array}\right. \\
& \Longrightarrow \quad p(j, l) \leq U p(k, m)+V p(k, F(k))+C p(m, F(m)) \\
& +D p(k, F(m))+W p(m, F(k)) .
\end{aligned}
$$

Definition 2.10 Let $(A, B)$ be a pair of non-empty subsets of an $S$-complete Hausdorff uniform space $(X, \Gamma)$ such that $p$ is an $E$-distance on $X$. Suppose that $F: A \rightarrow B$ and $G: B \rightarrow A$ are mappings. The pair $(F, G)$ is said to be a Hardy-Rogers $p$-proximal cyclic contraction if there exist non-negative real constants $U, V, C, D, W$ such that $U+V+C+D+W<1$ and for all $j, k \in A$ and $l, m \in B$,

$$
\begin{aligned}
& \left\{\begin{array}{l}
p(j, F(k))=p(A, B) \\
p(l, G(m))=p(A, B)
\end{array}\right. \\
& \Longrightarrow \quad p(j, l) \leq U p(k, m)+V p(k, F(k)) \\
& +C p(m, G(m))+D p(k, G(m))+W p(m, F(k)) \\
& +(1-U-V-C-D-W) p(A, B) \text {. }
\end{aligned}
$$

It is easy to see that a self-mapping that is a proximal Hardy-Rogers contraction is a Hardy and Rogers contraction. But a non-self $p$-proximal Hardy-Rogers contraction is not necessarily a Hardy and Rogers contractive map. Also, (2.8) and (2.7) reduce to the Reich contraction map if $A=B, S=T, D=W=0$, in (2.8) and (2.7). Furthermore, the contractive condition (2.7) reduces to (2.4) if the $E$-distance $p$ is replaced with a metric $d$, in the sense that if we set $\Gamma=\left\{(x, y) \in X^{2}: d(x, y)<\epsilon\right\}$ in (2.7), then we obtain (2.4).

The following definition is needed for our work.

Definition 2.11 Let $A, B$ be two non-empty subsets of an $S$-complete Hausdorff uniform space $(X, \Gamma)$. Suppose that $S: A \rightarrow B$ and $g: A \rightarrow A$ are isometry, the mapping $S$ is said to preserve the isometric distance with respect to $g$ if

$$
p(S(g(x)), S(g(y)))=p(S(x), S(y)) \quad \forall x, y \in A .
$$

\section{Main results and discussion}

This research is limited to mappings defined in uniform spaces. The study is theoretical and analytical based and centred on mappings satisfying contractive like conditions. However, applications to real life are not within the scope.

Now we state and prove the main results.

Theorem 3.1 Let $(X, \Gamma)$ be a Hausdorff uniform space and $p$ an E-distance on X. Suppose that $(A, B)$ is a pair of non-empty closed subsets of the p-bounded and $S$-complete space $(X, \Gamma)$ such that $A_{0}, B_{0} \neq \emptyset$. Let $F: A \rightarrow B, G: B \rightarrow A$ and $h: A \cup B \rightarrow A \cup B$ satisfy the following conditions:

(i) F and $G$ are p-proximal Hardy-Rogers contractions; 
(ii) $h$ is an isometry;

(iii) the pair $(F, G)$ is a p-proximal Hardy-Rogers cyclic contraction (2.8);

(iv) $F\left(A_{0}\right) \subseteq B_{0}, G\left(B_{0}\right) \subseteq A_{0}$;

(v) $A_{0} \subseteq h\left(A_{0}\right)$ and $B_{0} \subseteq h\left(B_{0}\right)$.

Then there exist unique points $x \in A$ and $y \in B$ such that

$$
p(h(x), F(x))=p(h(y), G(y))=p(x, y)=p(A, B) .
$$

Moreover, for any best proximity point $x_{0} \in A_{0}$, the sequence $\left\{x_{n}\right\}$ defined by

$$
p\left(h\left(x_{n+1}\right), F\left(x_{n}\right)\right)=p(A, B)
$$

converges to the element $x$.

Similarly, for any best proximity point $y_{0} \in B_{0}$, the sequence $\left\{y_{n}\right\}$ defined by

$$
p\left(h\left(y_{n+1}\right), G\left(y_{n}\right)\right)=p(A, B)
$$

converges to the element $y$.

Proof Let $x_{0} \in A_{0}$, since $A_{0} \neq \emptyset$ and $F\left(A_{0}\right) \subseteq B_{0}$, there exists $x_{1} \in A_{0}$ such that $p\left(x_{1}, F\left(x_{0}\right)\right)=$ $p(A, B)$. Also, since $F\left(x_{1}\right) \in B_{0}$, there exists $x_{2} \in A_{0}$ such that $p\left(x_{2}, F\left(x_{1}\right)\right)=p(A, B)$. Furthermore, we obtain a sequence $\left\{x_{n}\right\} \subset A_{0}$ such that $p\left(x_{n+1}, F\left(x_{n}\right)\right)=p(A, B) \forall n \in N$. We show that $\left\{x_{n}\right\}$ is a $p$-Cauchy complete sequence whose limit is the unique best proximity point of $F$. Since $F$ is a $p$-proximal Hardy-Rogers cyclic contraction, $\forall n \in N$, we have

$$
\begin{aligned}
& p\left(x_{n+1}, F\left(x_{n}\right)\right)=p(A, B), \\
& p\left(x_{n}, F\left(x_{n-1}\right)\right)=p(A, B)
\end{aligned}
$$

imply

$$
\begin{aligned}
p\left(x_{n+1}, x_{n}\right) \leq & U p\left(x_{n}, x_{n-1}\right)+V p\left(x_{n}, F\left(x_{n}\right)\right)+C p\left(x_{n-1}, F\left(x_{n-1}\right)\right) \\
& +D p\left(x_{n}, F\left(x_{n-1}\right)\right)+W p\left(x_{n-1}, F\left(x_{n}\right)\right) \\
& +[1-(U+V+C+D+W) p(A, B) \\
\leq & U p\left(x_{n}, x_{n-1}\right)+V\left[p\left(x_{n}, x_{n+1}\right)+p\left(x_{n+1}, F\left(x_{n}\right)\right)\right] \\
& +C\left[p\left(x_{n-1}, x_{n}\right), p\left(x_{n}, F\left(x_{n-1}\right)\right)\right]+D p\left(x_{n}, F\left(x_{n-1}\right)\right) \\
& +W\left[p\left(x_{n-1}, x_{n}\right)+p\left(x_{n}, x_{n+1}\right)+p\left(x_{n+1}, F\left(x_{n}\right)\right)\right] \\
& +[1-(U+V+C+D+W)] p(A, B), \\
p\left(x_{n+1}, x_{n}\right) \leq & \frac{1}{1-(V+W)}\left[(U+C+W) p\left(x_{n-1}, x_{n}\right)+(V+W) p\left(x_{n+1}, x_{n}\right)\right. \\
& +(V+C+D+W) p(A, B)+[1-(U+V+C+D+W)] p(A, B)] .
\end{aligned}
$$


Thus, by induction,

$$
\begin{aligned}
p\left(x_{n+1}, x_{n}\right) \leq & \sum_{n \rightarrow 1}^{\infty}(V+W)^{n}\left[(U+C+V)^{n} p\left(x_{0}, x_{1}\right)\right. \\
& \left.+\left[1-(U)^{n}\right] p(A, B)\right]
\end{aligned}
$$

Since $U+C+V+D+W<1$, we have $\lim _{n \rightarrow \infty}(U+C+V+D+W)^{n}=0$ and $\sum_{n \rightarrow 1}^{\infty}(V+$ $W)^{n}=1$.

Hence,

$$
\lim _{n \rightarrow \infty} p\left(x_{n}, x_{n+1}\right)=p(A, B)
$$

Also, since $p$ is an $E$-distance, we have

$$
p\left(x_{n}, x_{m}\right) \leq p\left(x_{n}, x_{n+1}\right)+\cdots+p\left(x_{m-1}, x_{m}\right) .
$$

Now, for $\lambda \geq 1$,

$$
p\left(x_{n}, x_{n+\lambda}\right) \leq \eta^{n} p\left(x_{0}, x_{1}\right)+\cdots+\eta^{n+\lambda-1} p\left(x_{0}, x_{1}\right) .
$$

Let $C_{n}=\sum_{t=0}^{n} \eta^{t} p\left(x_{0}, x_{1}\right), n \geq 0$, then

$$
p\left(x_{n}, x_{n+\lambda}\right) \leq C_{n+\lambda-1}-C_{n-1} .
$$

Next, we show that $\left\{x_{n}\right\}$ is $p$-Cauchy in the $S$-complete space $X$, that is,

$$
\lim _{n \rightarrow \infty} p\left(x_{n}, x_{n+\lambda}\right)=0
$$

and

$$
\lim _{n \rightarrow \infty} p\left(x_{n+\lambda}, x_{n}\right)=0
$$

for any $\lambda \geq 1$.

Recall that

$$
p\left(x_{n+1}, F\left(x_{n}\right)\right)=p(A, B) .
$$

If there exists $n_{0} \in N$ such that $x_{n_{0}+1}=x_{n_{0}}$, we end the proof and $x_{n_{0}}$ is the required best proximity point of $F$. Therefore, we assume that $x_{n+1} \neq x_{n}$.

Suppose $p\left(x_{0}, x_{1}\right)>0$, now using inequality (3.2), we have

$$
\sum_{t=0}^{\infty} \eta^{t} p\left(x_{0}, x_{1}\right)<\infty
$$

So, there exists $C \in[0, \infty)$ such that $\lim _{n \rightarrow \infty} C_{n}=C$. 
Then, by (3.2),

$$
\lim _{n \rightarrow \infty} p\left(x_{n}, x_{n+\lambda}\right)=0
$$

Repeating the same argument, we obtain

$$
\lim _{n \rightarrow \infty} p\left(x_{n+\lambda}, x_{n}\right)=0
$$

So, the sequence $\left\{x_{n}\right\}$ is $p$-Cauchy in the $S$-complete space $(X, \Gamma)$.

Hence, $\left\{x_{n}\right\}$ converges to some element $x \in A$. Similarly, since $F\left(B_{0}\right) \subseteq A_{0}$ and $A_{0} \subseteq$ $h\left(A_{0}\right)$, there exists a sequence $\left\{y_{n}\right\}$ such that it converges to some element $y \in B$. Since the pair $(F, G)$ is a $p$-proximal Hardy-Rogers cyclic contraction and $h$ is isometry, by Lemma 2.4(b), we have

$$
p\left(h\left(x_{n+1}\right), F\left(x_{n}\right)\right)=p\left(h\left(y_{n+1}\right), G\left(y_{n}\right)\right)=p(A, B) .
$$

Then

$$
\begin{aligned}
p\left(h\left(x_{n+1}\right), h\left(y_{n+1}\right)\right)= & p\left(x_{n+1}, y_{n+1}\right) \\
\leq & U p\left(x_{n}, y_{n}\right)+V p\left(x_{n}, F\left(x_{n}\right)\right)+C p\left(y_{n}, G\left(y_{n}\right)\right) \\
& +D p\left(x_{n}, G\left(y_{n}\right)\right)+W p\left(y_{n}, F\left(x_{n}\right)\right)+(1-\mu) p(A, B),
\end{aligned}
$$

where $\mu=U+V+C+D+W$. Using Lemma 2.4(e) and taking limit as $n \rightarrow \infty$ in (3.4) yields

$$
p(x, y)=p(A, B)
$$

Thus, $x \in A_{0}$ and $y \in B_{0}$. Since $F\left(A_{0}\right) \subseteq B_{0}$ and $G\left(B_{0}\right) \subseteq A_{0}$, there exist $h(x) \in A$ and $h(y) \in B$ such that

$$
p(h(x), F(x))=p(A, B)
$$

and

$$
p(h(y), G(y))=p(A, B)
$$

Thus, from (3.5) and (3.6), we get

$$
p(x, y)=p(h(x), F(x))=p(h(y), G(y))=p(A, B) .
$$

Next, we prove the uniqueness of $x$ and $y$. Suppose that there exist $x^{*} \in A$ and $y^{*} \in B$ with $x \neq x^{*}$ and $y \neq y^{*}$ such that

$$
p\left(h\left(x^{*}\right), F\left(x^{*}\right)\right)=p(A, B)
$$


and

$$
p\left(h\left(y^{*}\right), G\left(y^{*}\right)\right)=p(A, B) .
$$

Since $h$ is an isometry and $F$ is a $p$-proximal Hardy-Rogers cyclic contraction, using equations (3.6), (3.7) and Lemma 2.4(b), we have

$$
\begin{aligned}
p\left(h(x), h\left(x^{*}\right)\right)= & p\left(x, x^{*}\right) \\
\leq & U p\left(x, x^{*}\right)+V p(x, F(x))+C p\left(x^{*}, F\left(x^{*}\right)\right) \\
& +D p\left(x, F\left(x^{*}\right)\right)+W p\left(x^{*}, F(x)\right)+(1-\mu) p(A, B) .
\end{aligned}
$$

$p\left(x, x^{*}\right) \leq \frac{(v+1-\mu)}{1-U} p(A, B)=p(A, B)$ as $v+1-\mu=1-U$, a contradiction, since $p(A, B)<$ $p\left(x, x^{*}\right)$. Recall that $\nu=V+C+D+W$ and $\mu=U+V+C+D+W$.

Hence, $p\left(x, x^{*}\right)=0$. Similarly, we show that $p\left(x^{*}, x\right)=0$. But since $p$ is an $E$-distance, we have

$$
p\left(x^{*}, x^{*}\right) \leq p\left(x^{*}, x\right)+p\left(x, x^{*}\right)
$$

Therefore,

$$
p\left(x^{*}, x^{*}\right)=0
$$

Now, we have $p\left(x^{*}, x^{*}\right)=0$ and $p\left(x, x^{*}\right)=0$. By Lemma 2.4(a), we conclude that $x^{*}=x$. Similarly, $y^{*}=y$.

Finally, we give some examples to show that inequalities (2.7) and (2.8) are distinct from inequalities (2.5), (2.6) and Kannan proximal cyclic contractions, respectively. The following examples support Theorem 3.1.

Example 3.2 Consider the space $X=R$ with Euclidean metric. Take the sets $A=[-8,-2]$ and $B=[2,8] \cup\{-12\}$. Note that $A_{0}=-2, B_{0}=2$. Clearly, $d(A, B)=4$. Let $F: A \rightarrow B$ and $G: B \rightarrow A$ be defined by

$$
F(x)=\left\{\begin{array}{ll}
\frac{24}{x}, & x<0, \\
-\frac{16}{x}, & x>0,
\end{array} \quad \text { and } \quad G(y)=-\frac{14}{y} .\right.
$$

Clearly, taking $x_{1}=-8, x_{2}=-2, y_{1}=2$ and $y_{2}=7, d\left(x_{1}, F\left(x_{2}\right)\right)=d\left(y_{1}, G\left(y_{2}\right)\right)=d(A, B)=4$. We show that the pair $(F, G)$ defined on a metric space is not a Hardy-Rogers proximal cyclic contraction. Clearly, by (2.8),

$$
\begin{aligned}
d\left(x_{1}, y_{1}\right) \leq & U d\left(x_{2}, y_{2}\right)+V d\left(x_{2}, F\left(x_{2}\right)\right)+C d\left(y_{2}, G\left(y_{2}\right)\right)+D d\left(x_{2}, G\left(y_{2}\right)\right) \\
& +W d\left(y_{2}, F\left(x_{2}\right)\right)+(1-\eta) d(A, B),
\end{aligned}
$$

where $\eta=U+V+C+D+W<1$.

$$
\begin{aligned}
d(-8,2) \leq & U d(-2,7)+V d(-2,-12)+C d(7,-2)+D d(-2,-2)+W d(7,-12) \\
& -4[U+V+C+D+W]+(1-\eta) 4
\end{aligned}
$$


However,

$$
10>9 U+10 V+9 C+0+19 W+(1-\eta) 4,
$$

a contradiction. For example, choose $U=\frac{1}{30}, V=\frac{1}{45}, C=\frac{1}{18}, D=\frac{1}{2}, W=\frac{1}{5}$, clearly $U+V+$ $C+D+W<1$.

Thus, $(F, G)$ is not a Hardy-Rogers proximal cyclic contraction. Clearly, $(F, G)$ has no best proximity point since there is no $x \in A$ and $y \in B$ such that $d(x, F(x))=d(y, G(y))=4$.

Now, we consider the case where $(F, G)$ is defined on a uniform space and $X, A$ and $B$ are defined as above.

Suppose that $p$ is defined as follows:

$$
p(x, y)= \begin{cases}\left|\frac{x}{2}\right|, & x \in A, y \in B \\ |2 y|, & \text { otherwise. (Note that } P(A, B)=1 .)\end{cases}
$$

We show that $(F, G)$, defined on a uniform space, is not a Reich proximal cyclic contraction

$$
\begin{aligned}
& p\left(x_{1}, y_{1}\right) \leq U p\left(x_{2}, y_{2}\right)+V p\left(x_{2}, F\left(x_{2}\right)\right)+C p\left(y_{2}, G\left(y_{2}\right)\right) \\
& +(1-(U+V+C)) p(A, B), \\
& p(-8,2) \leq U p(-2,7)+V p(-2,-12))+C p(7,-2))+(1-(U+V+C))(1) \text {. }
\end{aligned}
$$

However,

$$
4>U(1)+V(1)+C(1)+(1-(U+V+C))(1) .
$$

A contradiction, since $(U+V+C)<1 .(F, G)$ is not a Reich proximal cyclic contraction.

It is not difficult to see that $(F, G)$ satisfies the Hardy-Rogers $p$-proximal cyclic contraction for all $x \in A$ and $y \in B$, and -2 is the unique best proximity point of $F$, while 2 is the unique best proximity point of $G$ and $p(A, B)=1$.

From the example, we see that:

$$
\begin{aligned}
A_{0} & =\{x \in A: p(x, y)=p(A, B) \text { for some } y \in B\} \\
& =\{x \in A: p(x, y)=1 \text { for some } y \in B\}, \\
A_{0} & =\{-2\}, \\
B_{0} & =\{y \in B: p(x, y)=1 \text { for some } x \in A\} \\
& =B .
\end{aligned}
$$

Therefore, the Hardy-Rogers $p$-proximal cyclic contraction is more general than the Hardy-Rogers cyclic contraction and the Reich proximal cyclic contractions.

Example 3.3 Consider the complete metric space $R^{2}$ with the metric defined by

$$
d\left(\left(x_{1}, x_{2}\right),\left(y_{1}, y_{2}\right)\right)=\left|x_{1}-y_{1}\right|+\left|x_{2}-y_{2}\right| \quad \forall\left(x_{1}, x_{2}\right),\left(y_{1}, y_{1}\right) \in R^{2} .
$$


Let

$$
A=\{(0, x): x \in R\}, \quad B=\{(5, y): y \in R\} .
$$

Define the mapping $F: A \rightarrow B, G: B \rightarrow A, h: A \cup B \rightarrow A \cup B$ as follows:

$$
F(0, x)=\left(5, \frac{5|x|}{1+|x|}\right), \quad G(5, y)=\left(0, \frac{5|y|}{1+|y|}\right) \quad \text { and } \quad h(x, y)=(x,-y)
$$

Then $d(A, B)=5, A_{0}=A, B_{0}=B$ and the mapping $h$ is isometry.

Now, we show that the pair $(F, G)$ defined on a complete metric space is not a proximal Hardy-Rogers cyclic contraction.

Let $(0, u),(0, x) \in A$ and $(0, v),(0, y) \in B$ satisfying

$$
\begin{aligned}
& d((0, u), F(0, x))=d(A, B)=5, \\
& d((0, v), G(0, y))=d(A, B)=5 .
\end{aligned}
$$

Then, we get $u=\frac{5|x|}{1+|x|}, v=\frac{5|y|}{1+|y|}$.

Also,

$$
\begin{aligned}
d((0, u), d(5, v))= & |u-v|+5 \\
= & \left|\frac{5|2 x-x|}{1+|x|}-\frac{5|2 y-y|}{1+|y|}\right|+5 \\
= & \left|\frac{5 \mid x+x-x-y-y+y) \mid}{(1+|x|)(1+|y|)}\right|+5 \\
\leq & \frac{5(|x-y|+|x-y|+|y-x|+|x-x|+|y-y|)}{(1+|x|)(1+|y|)}+5 \\
\leq & 5(|x-y|+|x-F(x)|+|y-G(y)|+|x-G(y)|+|y-F(x)|)+5 \\
& \quad \operatorname{taking} y=F(x), x=G(y) \\
> & a_{1}|x-y|+a_{2}|x-F(x)|+a_{3}|y-G(y)|+a_{4}|x-G(y)| \\
& \left.+a_{5}|y-F(x)|+5\right)+(1-\eta) 5, \eta=a_{1}+a_{2}+a_{3}+a_{4}+a_{5} \\
= & a_{1} d((0, x),(0, y))+a_{2} d((0, x), S(0, x))+a_{3} d((0, y), G(0, y)) \\
& +a_{4} d((0, x), G(0, y))+a_{5} d((5, y), G(5, x))+(1-\eta) d(A, B), \quad \eta<1,
\end{aligned}
$$

a contradiction.

Hence $(F, G)$ is not a proximal Hardy-Rogers cyclic contraction.

Now defining $(F, G)$ on a uniform space and letting

$$
p\left[\left(x_{1}, x_{2}\right)\left(y_{1}, y_{2}\right)\right]= \begin{cases}\frac{\left|x_{1}-y_{1}\right|}{17}+\frac{\left|x_{2}-y_{2}\right|}{17}, & x_{1}, x_{2}, y_{1}, y_{2} \in N \cup\{0\} \\ \left|x_{1}-y_{1}\right|+\left|x_{2}-y_{2}\right|, & x_{1}, x_{2}, y_{1}, y_{2} \in Q \\ \frac{\left|x_{1}-y_{1}\right|}{17}+\left|x_{2}-y_{2}\right|, & \text { otherwise. }\end{cases}
$$


Then

$$
\begin{aligned}
p((0, u), p(5, v)) \leq & a_{1} p((0, x),(0, y))+a_{2} p((0, x), S(0, x))+a_{3} p((0, y), G(0, y)) \\
& +a_{4} p((0, x), G(0, y))+a_{5} p((5, y), G(5, x))+(1-\eta) p(A, B), \quad \eta<1,
\end{aligned}
$$

is true for all $x \in A$ and $y \in B$.

$(F, G)$ is a Hardy-Rogers $p$-proximal cyclic contraction and $(0,0) \in A,(5,0) \in B$ are the unique best proximity points such that

$$
p(h(0,0), F(0,0))=p(h(5,0), G(5,0))=p((0,0),(5,0))=p(A, B) .
$$

The following corollaries further show that our theorem extends many known results in literature.

Corollary 3.4 ([20]) Let $(X, d)$ be a complete metric space. Suppose $T: A \cup B \rightarrow A \cup B$ satisfies $p(T(x), T(y)) \leq k d(x, y)+(1-k) d(A, B), k \in(0,1)$, then $T$ has a unique best proximity point.

Proof Set $\Gamma=\left\{(x, y) \in X^{2}: d(x, y)<\epsilon\right\}$, and suppose $F=G=T, j=T(x), l=T(y)$ and $V=$ $C=D=W=0$ in inequality (2.8), then the result follows.

Remarks The result also follows when $A$ and $B$ are nonempty closed convex subsets of a uniformly convex space [11].

Corollary 3.5 ([16]) Let $(X, d)$ be a metric space and $A, B$ be two nonempty closed subsets of $X$. Let $T: A \cup B \rightarrow A \cup B$ be a Reich type cyclic contraction, then $T$ has a unique fixed point in $A \cap B$.

Proof The proof is complete by taking $D=W=0, U=V=C=k, F=T, j=T(x), l=T(y)$, $p(A, B)=0$, and setting $\Gamma=\left\{(x, y) \in X^{2}: d(x, y)<\epsilon\right\}$ in inequality (2.8).

Corollary 3.6 ([13]) Let $(X, d)$ be a complete metric space and $A, B$ be two nonempty closed subsets of $X$. Let $T: X \rightarrow X$ be a Hardy and Rogers contraction, that is, if there exist non-negative constants $a_{i}(i=1,2,3,4,5)$ such that $a_{1}+a_{2}+a_{3}+a_{4}+a_{5}<1$ satisfy$\operatorname{ing} d(T(x), T(y)) \leq a_{1} d(x, y)+a_{2} d(x, T(x))+a_{3} d(y, T(y))+a_{4} d(x, T(y))+a_{5} d(y, T(x))$ for all $x, y \in X$, then $T$ has a unique fixed point.

Proof The proof of this corollary follows by taking $A=B, F=G=T$ and setting $\Gamma=$ $\left\{(x, y) \in X^{2}: d(x, y)<\epsilon\right\}$ in inequality (2.7).

Corollary 3.7 Let $(A, B)$ be a pair of non-empty subsets of an S-complete Hausdorff uniform space $(X, \Gamma)$ such that $p$ is an E-distance on $X$. Suppose that $F: A \rightarrow B$ and $G: B \rightarrow A$ are mappings satisfying one of the following conditions:

(a) $(F, G)$ is a p-proximal cyclic contraction;

(b) $(F, G)$ is a Kannan p-proximal cyclic contraction;

(c) $(F, G)$ is a Chatterjea p-proximal cyclic contraction;

(d) $(F, G)$ is a Reich p-proximal cyclic contraction. 
Then there exists a unique point $x \in A$ and $y \in B$ such that $p(x, F(x))=p(y, G(x))=p(A, B)$. Moreover, for any best proximity point $x_{0} \in A_{0}$, the sequence $\left\{x_{n}\right\}$ defined by $p\left(x_{n+1}, F\left(x_{n}\right)\right)=$ $p(A, B)$ converges to the element $x$. Similarly, for any best proximity point $y_{0} \in B_{0}$, the sequence $\left\{y_{n}\right\}$ defined by $p\left(y_{n+1}, G\left(y_{n}\right)\right)=p(A, B)$ converges to the element $y$.

Proof Taking (a) $V=C=D=W=0$ and $j=T(x), l=T(y)$ in inequality (2.8), we obtain Corollary 3.7(a);

(b) $C=D=W=0$ and $j=T(x), l=T(y)$ in inequality (2.8), we obtain Corollary 3.7(b);

(c) $U=V=C=0$ and $j=T(x), l=T(y)$ in inequality (2.8), we obtain Corollary 3.7(c);

(d) $D=W=0$ and $j=T(x), l=T(y)$ in inequality (2.8), we obtain Corollary 3.7(d).

\section{Conclusion}

In this work, we have investigated the best proximity point results for Hardy-Rogers $p$ proximal cyclic contraction in uniform spaces. This provides a positive answer to the question of whether best proximity point results for Hardy and Rogers type mappings could be established in uniform spaces. We also gave corollaries and examples to show that the best proximity point results for Hardy and Rogers type mappings in literature become simple consequences of this result. We hope that the findings in this paper will help researchers enhance and promote the further studies on best proximity point of more maps in uniform spaces and other more general spaces to carry out a general framework for their applications in real life.

Acknowledgements

The authors wish to sincerely thank the referee for the useful comments leading to the improvement of this paper.

Funding

This article is funded by the authors.

Abbreviations

Not applicable.

Declaration

This article is original and genuine research. The authors permit the editors to publish this article.

Availability of data and materials

Data sharing is not applicable to this research as no datasets was generated or analysed during the current study.

Competing interests

The authors declare that they have no competing interests.

Authors' contributions

All authors contributed equally and significantly in writing this article. All authors read and approved the final manuscript.

Author details

'Department of Mathematics, Adeniran Ogunsanya College of Education, Lagos, Nigeria. ${ }^{2}$ Department of Mathematics, University of Lagos, Lagos, Nigeria. ${ }^{3}$ Department of Mathematics, Covenant University, Ota, Nigeria.

\section{Publisher's Note}

Springer Nature remains neutral with regard to jurisdictional claims in published maps and institutional affiliations.

Received: 26 January 2018 Accepted: 20 July 2018 Published online: 06 August 2018

\section{References}

1. Aamri, M., El Moutawakil, D.: Common fixed point theorems for E-contractive or E-expansive maps in uniform spaces. Acta Math. Acad. Paedagog. Nyházi. 20(1), 83-89 (2004) (electronic)

2. Amini-Harandi, A.: Best proximity point theorem for cyclic strongly quasi-contraction mappings. J. Glob. Optim. (2012). https://doi.org/10.1007/s10898-012-9953-9 
3. Amini-Harandi, A., Hussain, N., Akbar, F.: Best proximity point results for generalised contractions in metric spaces. Fixed Point Theory Appl. 2013, Article ID 164 (2013)

4. Banach, S.: Sur les operations dans les ensembles abstraits et leurs applications aux equations integrales. Fundam. Math. 3, 133-181 (1922)

5. Basha, S.S.: Best proximity points: optimal solution. J. Optim. Theory Appl. 151(1), 210-216 (2011)

6. Bourbaki, N.: Topologie generale, Chapitre 1: Structures topologiques, Chapitre 2: Structures uniformes, 4th edn. Actualites Scientifiques et Industrielles, vol. 1142. Hermann, Paris (1965)

7. Chatterjea, S.: Fixed points theorems. C. R. Acad. Bulgare Sci. 25, 727-730 (1972)

8. Cho, S., Bae, J., Karapinar, E.: Fixed point theorem of $\alpha$-Geraghty contractive maps in metric spaces. Fixed Point Theory Appl. (2013). https://doi.org/10.1186/1687-1812-2013-329

9. Ciric, L.B.: Generalised contractions and fixed-point theorems. Publ. Inst. Math. (Belgr.) 12(26), 19-26 (1971)

10. Dhagat, V.B., Singh, V., Nath, S.: Fixed point theorems in uniform space. Int. J. Math. Anal. 3(4), 197-202 (2009)

11. Eldred, A.A., Veeramani, P.: Existence and convergence of best proximity points. J. Math. Anal. Appl. 323(2), 1001-1006 (2006)

12. Gnana-Bhaskar, T., Lakshmikantham, V.: Fixed points theorem in partially ordered metric spaces and application. Nonlinear Anal. 65, 1379-1393 (2006)

13. Hardy, G., Rogers, T.: A generalisation of a fixed point theorem of Reich. Can. Math. Bull. 16, 201-206 (1973)

14. Hussain, N., Karapinar, E., Sedghi, S., Shobkolaei, N., Firouzian, S.: Cyclic $(\phi)$-contractions in uniform spaces and related fixed point results. Abstr. Appl. Anal. 2014, Article ID 976859 (2014)

15. Kannan, R.: Some results on fixed points. Bull. Calcutta Math. Soc. 10, 71-76 (1968)

16. Karapinar, E., Erhan, I.M.: Best proximity point on different type of contractions. Appl. Math. Inf. Sci. 5(3), 558-569 (2011)

17. Karpagam, S., Agrawal, S.: Best proximity point theorem for $p$-cyclic Meir-Keeler contraction. Fixed Point Theory Appl. 2009, Article ID 197308 (2009)

18. Kiany, F., Amini-Harandi, A.: Fixed point theory for generalised Ciric quasi-contraction maps in metric spaces. Fixed Point Theory Appl. (2013). https://doi.org/10.1186/1687-1812-2013-26

19. Kirk, W.A., Srinavasan, P.S., Veeramani, P.: Fixed points for mapping satisfying cyclical contractive conditions. Fixed Point Theory Appl. 4, 79-89 (2003)

20. Mihaela, A.P.: Best proximity point theorem for weak cyclic Kannan contractions. Filomat 25(1), 145-154 (2011)

21. Mongkolkeha, C., Cho, Y.J., Kumam, P.: Best proximity point for Geraghty's proximal contraction mappings. Fixed Point Theory Appl. (2013). https://doi.org/10.1186/1687-1812-2013-180

22. Olaleru, J.O.: Approximation of common fixed points of weakly compatible pairs using the Jungck iteration. Appl. Math. Comput. 217, 8425-8431 (2011)

23. Olaleru, J.O., Olisama, O.V., Abbas, M.: Coupled best proximity points for generalised Hardy-Rogers type cyclic (w)-contraction. Int. J. Math. Anal. Optim. 1, 33-54 (2015)

24. Olisama, V.O., Olaleru, J.O., Akewe, H.: Best proximity points results for some contractive mappings in uniform spaces. Int. J. Anal. 2017, Article ID 6173468 (2017)

25. Olisama, V.O., Olaleru, J.O., Olaoluwa, H.: Quadruple best proximity points of Q-cyclic contraction pair in abstract metric spaces. Asian J. Math. Appl. 2015, Article ID ama0206 (2015)

26. Pragadeeswarar, V., Poonguzali, G., Marudai, M., Radenovic, S.: Common best proximity point theorem for multivalued mappings in partially ordered metric spaces. Fixed Point Theory Appl. (2017). https://doi.org/10.1186/s13663-017-0615-y

27. Raj, V.S.: A best proximity point theorem for weakly contractive non-self mappings. Nonlinear Anal., Theory Methods Appl. 74(14), 4804-4808 (2011)

28. Reich, S.: Some remarks concerning contraction mappings. Can. Math. Bull. 14, 121-124 (1971)

29. Rhoades, B.E.: A comparison of various definitions of contractive mappings. Trans. Am. Math. Soc. 226, 257-290 (1977)

30. Suzuki, T., Kikkawa, M., Vetro, C.: The existence of best proximity point in metric spaces with the property UC. Nonlinear Anal. 71, 2918-2926 (2009)

31. Weil, A.: Sur les espaces a structure uniforme et sur la topologie generale. Actualites Scientifiques et Industrielles, vol. 551. Hermann, Paris (1937)

32. Zamfirescu, T.: Fixed point theorems in metric spaces. Arch. Math. (Basel) 23, 292-298 (1972)

\section{Submit your manuscript to a SpringerOpen ${ }^{\circ}$ journal and benefit from:}

- Convenient online submission

- Rigorous peer review

- Open access: articles freely available online

- High visibility within the field

- Retaining the copyright to your article

Submit your next manuscript at $\gg$ springeropen.com 